\title{
Scripted Reality: How Observers Make Sense of a Non-consensual Sexual Encounter
}

\author{
Eva Mulder ${ }^{1,2}$. Stephanie Olsohn ${ }^{2}$ \\ Accepted: 3 November 2020 / Published online: 23 November 2020 \\ (C) The Author(s) 2020
}

\begin{abstract}
Research on third party reactions to (transgressive) sexual encounters has frequently bypassed the question of how observers categorize such encounters as normal sexual experience, sexual violence, or potentially as something else. In the present study, we investigated the ways in which participants made sense of a nonconsensual sexual encounter between a man (i.e., the initiating party) and either a male or a female student (i.e., the targeted party). We specifically focused on how participants utilized sexual scripts and gender stereotypes to describe what happened and as a means of attributing responsibility to the actors. Using the Articulated Thoughts in Simulated Situations (ATSS) technique, 52 Dutch participants ( 26 men and 26 women) responded aloud to a vignette. Data were analyzed using discourse analysis as employed in discursive psychology. The findings demonstrated that participants constructed the event described in the vignette as normal while depicting the targeted party as abnormal and accountable. Participants strategically employed sexual scripts and gender stereotypes to describe the event as predictable and not serious and the initiating party's actions as in little need of explanation. The targeted party was positioned as detached from this "objective reality" and was held accountable for neither following nor sufficiently breaking with the script. In consequence, the event was rendered nonthreatening. Our results illustrated the ways in which predominant discourses influence interpretations of encounters as transgressive or "just" sex, having important implications for those who seek to share their experiences of sexual violation.
\end{abstract}

Keywords Discursive psychology $\cdot$ Third party sense-making $\cdot$ Nonconsensual sex $\cdot$ Grey area $\cdot$ Gender

In this day and age, the identification of and adequate responses to claims of (severe) sexual assault have become ever more a priority. Recent movements such as Time's up (https:// timesupnow.org/), \#Yesallwomen, and \#MeToo have emphasized the scope of sexual violence - not just in terms of the vast number of victims affected, but also as descriptions of the many possible shapes and forms of sexual violence. Additionally, several stories have been featured in the news and media that largely defy unambiguous labeling as either normal sex or sexual transgression. The fictional short story, "Cat Person" in 2017, one of the most read pieces in The New Yorker, is an exemplary narration of a deeply uncomfortable

Eva Mulder

e.mulder@tilburguniversity.edu

1 Tilburg Law School, Tilburg University, Tilburg, the Netherlands

2 Leiden Law School, Leiden University, Leiden, the Netherlands sexual encounter that is generally not designated as a story of rape (Roupenian 2017). A non-fictional account of a similar experience has been given by a young woman with the pseudonym Grace. In an interview in January 2018, she related her experiences during a date with actor and comedian Aziz Ansari, concluding that his behavior had made her feel violated and that she had come to see the event as sexual assault (Way 2018). These stories have received a large and widely varied response in the media (Silman 2018; Walsh and Murphy 2019; Worthington 2020).

To describe "ambiguous" sexual encounters such as those we mentioned, several authors have used the term "grey area" (Cahill 2016; Gavey 2005; Sessions Step 2007). This grey area encompasses varying experiences that seem to fall somewhere between desired or consensual sex and encounters that are commonly acknowledged as clearly sexual assault or rape. These encounters generally do not include (threats of) physical violence, but may include more subtle forms of coercion such as manipulation or "nagging" to such an extent that the other party is "worn down." This other party may be reluctant 
or unwilling to have sex but feel that it is impossible or disadvantageous to refuse (Cahill 2016; Gavey 2005; Kahn et al. 2003). Although something may feel "off," such ambiguous encounters generally hinder the sure identification of, and distinction between, a victim and a perpetrator. As such, these grey area sexual encounters are likely to signify a (moral) situation that is not "clear-cut," and are therefore particularly demanding of observers' sense-making practices and judgment formation.

To date, most research on observer reactions to (victims of) sexual violence has employed relatively brief vignettes that provide a "factual account" of rape, followed by closedended response scales that aim to determine the extent to which participants blame the victim (Anderson and Doherty 2008). However, little is known about how observers make sense of such scenarios and what types of resources they draw upon to construe more ambiguous nonconsensual sexual encounters as "normal" sexual experience, sexual violence, or potentially as something else. One important sense-making resource is likely to be found in "scripts": descriptions of how a given (sexual) situation will "typically" develop (Frith and Kitzinger 2001; Simon and Gagnon 1986). Scripts can be utilized by observers to identify and explain both normative (e.g., the traditional sexual script) and transgressive (e.g., the "real rape" script) sexual encounters between men and women. In those scripts, stereotypical gender roles form a key element (Wiederman 2005).

Whereas academic research on the construction of nonconsensual sexual encounters between men and women is scarce, even less attention has been paid to sense-making of nonconsensual sexual encounters between men. We might expect that fewer sexual scripts are available for observers who attempt to make sense of these encounters compared to sexual encounters between men and women, particularly when they include ambiguous elements. Observers may have difficulty constructing such scenarios as consensual sex because information about intimate (sexual) relations between men is less available in common discourse. The same scenarios may also challenge constructions as sexual violence because male (sexual) victimization is considered inherently nonnormative and far-removed from the expected and prescribed roles of men in sexual encounters (Doherty and Anderson 2004; Mulder and Bohner 2020).

In the present study, we investigated how observers made sense of and navigated their moral judgments in response to a particular grey area nonconsensual sexual encounter. We additionally investigated potential differences in how observers made sense of this encounter between a man and woman or between two men. We use the term "grey area" to refer to the vignette in our study, not as a pre-categorization of the event, but to indicate our expectation that the described encounter resists easy categorization in current-day discourses about sex and violence (Gunnarsson 2018; Hindes and Fileborn 2020).
The present research takes social constructionism as its epistemological starting position, treating language not as a reflection of an objective reality, but as an instrument that shapes our (inter)subjective realities (Crotty 1998). However, because we contend that our vignette describes a situation of nonconsensual sex, our approach resembles one of contextual, rather than strict, constructionism where we "acknowledge making some assumptions about social conditions" (Best 1989, as cited in Loseke 1999, p. 206).

\section{Sexual Scripts}

Scripting has proved a useful conceptual tool in investigating how people make sense of sexual interactions. Scripts are "a metaphor for conceptualizing the production of behavior within social life" (Simon and Gagnon 1986, p. 98). They can help us to interpret, (re)frame, and create meaningful situations. In line with the social constructionist approach, we agree that:

Rather than understanding the "scripted" description as indicative of underlying mental representation, we can see it $[\ldots]$ as a contextually occasioned production, a way of discursively constructing events that attend to their attributional significance within a sequence involving responsibility and blame (Edwards and Potter 1992, p. 148; also Frith and Kitzinger 2001).

Scripts function on different levels: socially in terms of "prescribing what is considered normative within a culture, and as intrapsychic maps, providing directions for how to feel, think, and behave in particular situations" (Wiederman 2005, p. 496). Gagnon and Simon (1973) originally applied the concept of scripting to examine the development and experience of sexual behavior. Since then, sexual scripts have been viewed as ways of framing and making sense of a wide range of sexual scenarios, including transgressive ones (e.g., Marcus 1992).

Sexual scripts include those that describe "normal" sexual encounters, but also scripts that narrate sexual violence. Normative sexual scripts are based on the traditional sexual script, which revolves around a man who actively and/or aggressively pursues sex and a woman who functions as gatekeeper and must not "give in" to the man's desires too easily (Byers 1996). Notions like "playing hard to get" and "token resistance" derive from endorsement of this gendered script (Jackson 1978; Wiederman 2005). The script's differential gender role attribution also facilitates the likelihood that ethically ambiguous sexual encounters are explained in terms of miscommunication or misunderstanding between parties (Frith and Kitzinger 1997; Muehlenhard 1988). Originating from the traditional sexual script are various normative sexual scripts that describe casual sexual encounters between men 
and women (i.e., hookups). Hookup scripts describe sexual encounters between men and women who are usually not well acquainted or at least not involved in a romantic relationship with each other. Such scripts often include a meet-up at a bar or party, alcohol consumption and intoxication, going home together, and engaging in sexual activities (Holman and Sillars 2012).

\section{"Real Rape"}

Sexual violence or rape is generally scripted as a concrete experience clearly distinguished from normative sexual practice (Gash and Harding 2018; Gunnarsson 2018; Hindes and Fileborn 2020; Jackson 1978). This has been demonstrated, for instance, in experimental studies where participants were asked to describe what they believed to be typical seduction/ hookup and rape scenarios (Anderson 2007; Krahé et al. 2007; Littleton and Axsom 2003; Littleton et al. 2009; Ryan 1988). Participants in these studies frequently depicted a stranger rape when asked to describe a typical rape or sexual assault. To denote the type of event that is most readily identified as unambiguous sexual assault, authors have employed the term "real rape script" (Ryan 2011) or "real rape stereotype" (Temkin and Krahé 2008). This script generally includes a stranger rape which takes place outside at night and during which the perpetrator attacks suddenly and uses a weapon or excessive physical force. While fearing for her life, the victim in this script is described as struggling fiercely to fight off her attacker (Ryan 2011). Although such a stereotypical case of rape is far less common than cases of sexual violence between acquainted parties and with little or no physical force, it remains the prototype by which claims of sexual victimization are evaluated (Ryan 2011; Temkin and Krahé 2008).

Making sense of an experience or social interaction often involves a moral evaluation of the experience (Entman 1993). In the perception of (sexual) victimization, this sense-making involves the identification of a moral agent - the perpetrator-who harms a moral patient - the victim (Gray and Wegner 2009). The roles of victim and perpetrator are in direct and unambiguous opposition to each other (Christie 1986; Dunn and Powell-Williams 2007). Supporting this theorization is the finding that even in instances of mutual domestic violence, third parties such as care service providers and criminal justice authorities are inclined to approach the matter through the identification of a (female) victim and (male) perpetrator (Bates 2016). In the case of sexual transgression, both legally and socially, a broader range of sexual experiences has been recognized as unethical and victimizing in recent years, with factors such as physical force, resistance, and reporting to the police disappearing as necessary defining features (Caringella 2008). Still, even in cases that meet the legal definition for rape, difficulties seem to arise when people are tasked to make sense of "subjective experiences [that] do not fit neatly into the contextual framework of the cultural 'rape script"” (Deming et al. 2013, p. 466).

\section{Grey Area Sex}

Whereas our prior analysis describes an inclination to draw firm borders between what should be categorized as consensual or "normal" sex and what is assault, both in experience and in discourse, distinctions between ethical sex and sexual transgression can be muddled and confused. Sexual encounters such as described in the interview with Grace or in the short story "Cat Person," for instance, are not easily scripted as one thing or another. In the academic arena, several (feminist) philosophers have pondered the ethically ambiguous space between "normal" sexual encounters and those experienced or presented as rape or sexual assault. These scholars have referred to "unwanted sex," "unjust sex," or the "grey area" of sexual interaction to denote a wide range of undesired and ethically questionable sexual experiences (Cahill 2016; Gavey 2005). Kahn et al. (2003, p. 240), for instance, use the term "unwanted sex" to describe experiences of their female participants where they

did not want to have sexual intercourse with the man at that time, and they made that very clear to the man, often resisting for some time. The man did not use physical force or the threat of it; rather, he begged, pleaded, pouted, and argued until the women stopped resisting and gave in to the man's pressure.

According to Cahill (2016, p. 753), grey area sex is generally "marked by hesitation, reluctance, or an ambivalent kind of unwillingness."

Grey area sexual interactions often consist of experiences that feel wrong, but cannot be adequately described (by the experiencer or third parties) in the available (legal) terminology of what is permissible and what is not (Alcoff 2018; Gash and Harding 2018). Several feminist scholars have noted that the existence of a grey area of sexual interaction is characteristic of the intimate relationship between sexual violence and heteronormative sex. These scholars place "normal" (hetero)sexual practices and violent ones on one continuum (Gavey 2005; MacKinnon 1989). As Gunnarsson (2018, p. 7) notes, this grey area implies "both the sense that ['normal'] sex and violence are often difficult to distinguish in experience and the sense that the discursive scripting of hetero-sex and sexual violence overlap." Clearly, what is grey is up for negotiation, leaving observers with a lot of interpretative leeway to construct their chosen version of events.

The discursive overlap between normative sexual scripts and sexual violence has been demonstrated in qualitative 
studies (Jeffrey and Barata 2019; Lea and Auburn 2001) as well as many of the same experimental studies that highlighted participants' employment of "real rape" scripts (Littleton and Axsom 2003; Littleton et al. 2009; Ryan 1988). These studies showed that the seduction and hookup scripts written by participants shared notable features with what can be considered forced sex. For instance, both tended to include alcohol consumption, manipulative tactics by the man in order to obtain sex, and feelings of discomfort, shame, or remorse of the woman.

\section{Making Sense of Gender}

The sexual scripts we described take as their heteronormative starting point a passive woman and an active man. Indeed, stereotypical expectations of gender performances are essential to the logic of sexual scripts. As Burt and Estep (1981, p. 18) noted almost four decades ago, "a culture's patterns of belief about appropriate gender and sexual roles determine which interactions involving sexual behavior between individuals should be called victimization" (also see Alcoff 2014). To date, vignette studies that have conducted comparative investigations of targets' gender have mostly focused on male versus female victims of unambiguous stranger rape with a primary, almost exclusionary, focus on reactions of blame (overviews in Davies and Rogers 2006; Van der Bruggen and Grubb 2014). However, as has been pointed out by other researchers, traditional vignette studies that include quantitative and directed dependent measures may not adequately and comprehensively capture social reasoning about sexual violence (Anderson and Doherty 2008). Hence, such studies tell us little about the (gendered) sense-making practices that may lead to attributions of responsibility and blame.

To determine what counts as (male and female) victimization, to explain (away) sexual transgression, and to hold actors accountable, observers draw from interpretative repertoires (Wetherell and Potter 1988). Interpretative repertoires are the "cultural themes, arguments and assumptions" that form "the 'common sense' basis for shared understanding" (Anderson and Doherty 2008, pp. 65-66) and include sexual scripts, rape myths, and gender stereotypes (Lea and Auburn 2001). Potentially, observers selectively draw from interpretative repertoires and use different types of reasoning to make sense of (transgressive) sexual encounters between male-female or male-male dyads. Jeffrey and Barata (2019), for instance, argue that dominant social constructions of heterosexuality can function to justify and obfuscate sexual violence against women. Their findings revealed how male participants employed gender stereotypes such as men's uncontrollable sex drive and women's ineffective communication strategies to frame sexual violence as normal. The same constructions of heterosexuality and gender are presumably less effective in normalizing sexual violence against men. Furthermore, Reitz-Krueger et al. (2017, p. 315) speak of "gendered nuances" in the framing of male and female rape myths. Whereas female rape myths largely revolve around the notion of "asking for it," most male rape myths boil down to the key notion that ("real") men cannot be raped (Javaid 2015). The first set of myths employs a language of deservingness and blame, whereas the latter constructs responses around denial and derogation. Similarly, Anderson and Doherty (2008) found in their studies that different metaphors were employed when participants discussed the rape of a male student or a female student. Whereas female rape was frequently explained by scientific language that referred to the possibility of calculated risks and safety management, male rape was framed as "supernatural," where its occurrence could be neither foreseen nor reasonably protected against (p. 111).

Such findings seem to tap into the (non-)normativity of male and female sexual victimization. Whereas female rape victimization is mostly acknowledged as deeply unjust, it simultaneously describes a relatively common phenomenonone that may be accepted as a part of the "normal world." Male rape victimization, on the other hand, is likely to carry stronger connotations of non-normativity (Cohen 2014). Such non-normativity potentially demands different and/or more effortful sense-making strategies.

\section{The Current Study}

As we described, until now many studies that have examined social reasoning about (transgressive) sexual encounters (see an overview in Van der Bruggen and Grubb 2014) have used vignettes in combination with close-ended questionnaires (Anderson and Doherty 2008). However, designs that employ short, non-interactive vignettes may limit the understanding of the workings of observer sense-making practices because they prevent participants "from critically scrutinizing and discovering flaws in disagreeable information, interpreting the meaning of ambiguous information to be favorable in their viewpoint, [and] selectively searching through memory" (Rothgerber et al. 2020, p. 11). Such designs also tend to direct participants' attention toward the victim and toward specific reactions a priori selected by the researcher (Anderson and Doherty 2008). In appreciation of these concerns, several authors have employed qualitative response methods that are better able to capture subtleties in sense-making practices (e.g., Anderson and Doherty 2008; Deming et al. 2013). Anderson and Doherty (2008), for instance, collected conversational data about male and female rape, which they analyzed using discourse analysis. However, their vignette still presented a "clear-cut" violent stranger rape, leaving questions of people's reactions to more ambiguous sexual encounters unanswered. 
In light of this gap in the literature, we sought to investigate the ways in which people make sense of (i.e., describe and explain) a nonconsensual sexual encounter between a man (i.e., the initiating party) and a male or a female student (i.e., the targeted party). In order to do so, we conducted a qualitative study to examine how participants construed the event (i.e., What happened?) and in what ways they managed questions of accountability (i.e., Why did it happen in this way?). We specifically focused on how participants utilized sexual scripts and gender stereotypes to describe what happened and as a means of attributing responsibility to the actors. In order to answer these questions, we presented participants with an interactive vignette (based on a true account) that described a nonconsensual sexual encounter and left the targeted party feeling uncertain and ashamed.

\section{Method}

\section{Participants}

A total of 52 Dutch participants (26 men and 26 women) completed the study, of which 25 participants were randomly assigned to the female target condition (12 male and 13 female participants) and 27 (14 male and 13 female) participants to the male target condition. Their ages ranged between 18 and 28 years $(M=21.62, S D=2.22, m d n=22)$. With the exception of one participant, all were university students enrolled in varying bachelor or master programs.

\section{Procedure, Materials, and Measures}

Prior to data collection, our study was approved by the relevant ethics review board. Potential participants were recruited on university campus via flyers, which were spread throughout various buildings. In addition, announcements were posted on the websites of several faculties and on social media. During this recruitment process, participants were informed that the study involved questions about sexually inappropriate behavior and thus contained potentially sensitive information. Those who chose to participate could then contact the researchers to make an appointment for participation. Requirements for participation included fluency in Dutch and a minimum age of 18. Participants received a voucher of 10 euros, or, in the case of four psychology students, one research credit for their participation.

Upon arrival, participants were welcomed and seated in front of a computer. They subsequently read an information form about the study before signing an informed consent and reading the instructions for the ATSS procedure (see the following for more details). By means of the information form, participants were informed that the focus of the study was on "how people think about social interactions that include inappropriate (sexual) behavior" and that they would read a vignette that was based on interviews and newspaper articles published in recent years. Prior to starting the study, participants also read detailed instructions about every step of the ATSS procedure as outlined in the following. They were assured that there were no wrong answers and encouraged to voice every thought that came to mind, including thoughts that were not directly related to the vignette. Moreover, participants were informed that they could stop the procedure and/ or ask questions at any time during the experiment. After giving participants sufficient time to read the forms, the researcher ensured the participants had no further questions about the procedure, turned on the voice recorder, and seated herself right outside the room. The entire experiment lasted approximately 30 to $35 \mathrm{~min}$, and the participants were thoroughly debriefed by the researcher after its completion. All written material used in the study was in Dutch. Audio responses were transcribed verbatim and analyzed in Dutch.

\section{Vignette}

As part of the experiment, participants read a vignette divided into five fragments. The vignette described a story narrated from the perspective of a male or female student-Lisa or Lucas - who meets a male, relatively well-known DJThomas - at a party. After drinking and talking throughout the evening, Lisa/Lucas (L) goes home with Thomas, and ends up feeling pressured to perform oral sex on him. Shortly after, L leaves. (S)he does not report the incident to the police and describes feeling ashamed and guilty for not leaving sooner.

Numerous elements were included in the vignette in order to create a story that described an "ambiguous" nonconsensual sexual encounter. In the vignette, both $\mathrm{L}$ and Thomas were drinking alcohol at the party, paid for by Thomas ("he kept on ordering rounds of beer and gin tonic"; "L says they were both very tipsy at that moment"). L went home with Thomas after he "proposed to $L$ to have one more drink at his place." At Thomas' apartment, L told Thomas (s)he "did not want sex with him," but agreed to stay and watch TV after Thomas' first advances. In the vignette, $\mathrm{L}$ expressed that (s)he was bisexual, while Thomas' sexual orientation is left unmentioned. There was no mention of physical force, but Thomas continuously persisted in his advances (e.g., "it does not take long before Thomas moves closer again"). In response to some of these advances, "L does not react and keeps staring straight ahead" or "sat practically frozen on the couch." L also expressed nonconsent in various ways, both verbal (e.g., "when Thomas wants to take off L's jeans, L states again that (s)he does not want that"), and non-verbal (e.g., "that really startled me, I detached myself and stood up"; "I pushed his hand away a couple of times"). L also "admits" in the vignette that: "He remarked that I was wet [stiff] down there." Finally, when Thomas "asks for a blowjob," "L obeys a single minute, but 
then detaches her[him]self." L reflected in the vignette that (s)he felt ashamed and wondered "if I couldn't have left sooner."

The vignette was inspired by Grace's interview with the magazine Babe about her date with Aziz Ansari (Way 2018). (The complete vignette, both in its original Dutch and an English translation, can be found in the online supplement.) We based the vignette on this interview because we were interested in how people would react to stories about "grey area" sexual encounters as they have been portrayed online in recent years. In addition, Grace's interview was very lively and complex, and therefore it gave participants ample room to "interact" with information in the vignette and script their own versions of reality.

\section{Articulated Thoughts in Simulated Situations (ATSS)}

Participant reactions were elicited using the ATSS method (Davison et al. 1983; Zanov and Davison 2010). In ATSS, participants are required to respond spontaneously and aloud to a particular (audio, video or written) vignette during designated speaking breaks. With this method, participants could articulate their immediate and complex thoughts relatively unimpeded because they were not obliged to answer specific questions nor restricted by predetermined answering options (Anderson and Doherty 2008). Furthermore, this method does not necessitate the presence of another person, meaning that participants' responses were influenced by information in the vignette, their own experiences, and the social discourse available to them, but not by direct interaction with an interviewer or other conversation partner. We expected this approach to facilitate a setting in which participants could speak more freely about sensitive topics (Rayburn and Davison 2002).

The vignette in the current study was presented in fragments using the software program Qualtrics. The presentation of the fragments of the vignette was timed so that each one was displayed for a minimum of 20 or $30 \mathrm{~s}$, depending on the length of the fragment. After this time interval, an arrow appeared that allowed participants to proceed to the next fragment whenever they were ready. After each fragment, a oneminute break followed, during which the screen was blank except for the word "Break." In this time interval, participants provided their immediate reactions to the story by voicing their thoughts aloud. After one minute, the next fragment appeared automatically. The intermittent breaks within the vignette were expected to provide more insight into the elements on which participants focused to construct a version of events as the story developed. The timing of the ATSS break was based on previous research (Zanov and Davison 2010). A pilot study indicated that the time intervals were sufficiently long to allow participants to read each fragment of the vignette and to articulate responses. (Information about the exact placing of the breaks can be found in the online supplement.)

\section{Questionnaire}

After the entire vignette, participants completed a questionnaire consisting of ten items. Questions pertained to ratings of credibility, blame, distancing, and derogation of Lisa/Lucas, and to perceived crime severity, and Thomas' deserved punishment. Participants answered these questions both in a quantitative and qualitative manner. That is, they indicated their answers on a 7- point Likert scale, but also provided a spoken justification for why they selected a specific answer. Finally, participants answered several questions pertaining to demographic information. In light of the scope and aim of the present article, the responses to the questionnaire and the demographic data were not included in the analysis.

\section{Data Analysis}

Data were analyzed using discourse analysis as generally employed in discursive psychology (Anderson and Doherty 2008; Edwards and Potter 1992; Goodman 2017). Discourse analysis "is intended to do justice to the subtlety and complexity of lay explanations as they are deployed in natural contexts" (Wetherell and Potter 1988, p. 183). In line with our goal, discursive psychology focuses on discourse's action orientation and its (intended or unintended) consequences, rather than treating discourse as a reflection of individual cognition or motivation (Edwards and Potter 1993; Wetherell and Potter 1988). Its key aims are to examine "what is accomplished in talk" and how this is accomplished (Goodman 2017, p. 144).

In the course of careful repeated readings, we focused our analysis on what actions were accomplished in participants' accounts and through which discursive strategies they were accomplished. We specifically sought to identify information regarding how participants' described and evaluated the events and what interpretative repertoires (Wetherell and Potter 1988) they tapped into in their construction of events, including sexual scripts and related gender stereotypes. The discursive action model (DAM; Edwards and Potter 1993) guided our analytical approach. The DAM consists of three principles that aid in investigating attributional reasoning in everyday discourse. The first principle stresses that attributions in discourse should be studied as actions that accomplish something (e.g., manage questions of blame). The second principle underscores speakers as interested parties who 'manage 'interest' by performing attributions indirectly or implicitly" (p. 24), primarily by employing strategies to present their accounts as factual. The last principle highlights the role of agency and accountability, not only in the speaker's description and explanation of the events, but also as a key concern of the speaker him- or herself.

Our analysis focused exclusively on participants' ATSS data (i.e., their spontaneous reactions to the vignette). In initial readings, the first author broadly coded sections of the ATSS data in 
the software program MAXQDA (https://www.maxqda.com/). All descriptions of the event were coded, as well as descriptions of the actors and their behaviors, and explanations offered for these behaviors. Noting a tendency of participants to refer to what they found (ab)normal or (un)expected, a subsequent reading included coding descriptions and explanations as such. We conducted several lexical searches and quantitative comparisons, but because this was not the main focus or basis of our analysis, the broadly coded sections were then selected for detailed readings and critical analysis.

Discourse analysis, and qualitative data analysis more generally, is interpretatively demanding. To enhance the quality of our analysis and validity of our findings, we continuously moved back and forth between the data and our developing argument. Because the first author conducted the main part of the analysis, she discussed findings and interpretations with the second author in regular meetings. The first author additionally consulted an academic researcher who possessed expertise in psychological discourse analysis and social reasoning about sexual victimization. Realizing that our interpretations are not the only ones possible, we also included numerous verbatim extracts to enable readers to evaluate our arguments. All extracts have been labeled by number (\#), participant's gender (female: $\mathrm{F}$, and male: $\mathrm{M}$ ), and target condition (female target [Lisa]: FT; male target [Lucas]: MT).

\section{Results}

We found that participants generally portrayed the scenario presented in the vignette as nonthreatening. To do so, they strategically employed various discursive strategies to construct the situation as normal, L's response to the situation as abnormal, and (hence) $\mathrm{L}$ as responsible. A summary of these results can be found in Table 1. It is important to emphasize that although we uphold a certain structure in the reporting of our results, discursive strategies relating to the construction of

Table 1 Summary of results: Discursive accomplishments and strategies in participants' ATSS responses

Discursive accomplishment Description (including sub-strategies)

Discursive strategies

Event as Normal

Scripting as hookup

Distancing from sexual assault

Portraying Thomas' behavior as self-explanatory

$\mathrm{L}$ as Abnormal

Framing L's reaction as incomprehensible

Seeking explanations within L

$\mathrm{L}$ as Responsible

Emphasizing event as scripted

Appealing to L's agency

Comparison male and female target condition
The event resembles a normal sexual encounter, and is hence not particularly threatening.

Reference to a predictable sequence of events, which is likely to include sexual interaction (e.g., F29 FT); use of generalizing language; reference to "common knowledge" to indicate particular phrases and actions as signaling sexual intent (e.g., M40 MT; M36 FT).

Obscuring of coercive elements in vignette such as non-consent and oral sex (e.g., F6 FT); implicit contrasting of situation to "what could have happened" to diminish severity of event (e.g., F22 FT; F17 MT).

Alignment of Thomas' behavior with hookup script (e.g., M41 FT); reference to gender stereotypes to depict Thomas' behavior as unsurprising (e.g., M16 FT; F32 FT); employment of miscommunication discourse to diminish Thomas' intentionality and hence blameworthiness (e.g., M9 FT, F11 FT).

L's reaction to the situation is different from what can generally be expected, and $\mathrm{L}$ is "detached" from a nonthreatening reality.

Use of language such as "strange" and "naïve" and self-comparisons to emphasize L's abnormality. Suggestions that L's behavior requires explanation and justification (e.g., M9 FT, F1 MT).

Reference to factors such as alcohol, fear, and panic that locate the cause for L's behavior in L's (altered) state of mind rather than in external circumstances (e.g., F33 MT; M46 MT, M52 MT).

L should have been aware of how the event was likely to unfold and should have displayed more forceful attempts to resist sex and leave.

Reference to common knowledge and predictable sequence of events to emphasize L's responsibility to "accurately" read events and limit L's appropriate actions to counter progression of events, thereby holding $\mathrm{L}$ accountable (e.g., F2 FT; M31 MT).

Emphasis on ease with which L could have acted differently; formulations that express L's intentionality and agency (e.g., M47 FT; M30 MT; F13 FT).

The situation in the female target condition was constructed as following a more fixed sequence of events; Lisa was hence depicted as more responsible for knowing and breaking with the script in an "appropriate" manner. 
the events and to the accountability of the actors were interlinked.

In the following sections, we first discuss how participants constructed the event, including Thomas' actions, as normal in different senses of the word: It was framed as predictable, nonsevere, and in little need of explanation. Participants drew upon the hookup script to emphasize the predictable sequence of the events, and more implicitly employed the sexual assault script as contrasting discourse to diminish the severity of the event. Within this framework, Thomas' behavior was dismissed as in little need of explanation. Although participants generally contended that his actions were not what they ought to have been, many did not mark his behavior as particularly strange or unforeseeable, but rather portrayed it as largely in accordance with hookup behavior and gender stereotypes.

Subsequently, we focus on the ways in which participants constructed L as both abnormal and accountable. Participants implied that L's response to the situation was different from what might be expected, and they strategically portrayed L's behavior as incomprehensible through self-comparisons. Participants emphasized L's reaction as requiring justification, and they sought explanations within L's state of mind and personality, rather than in the potentially coercive circumstances. As such, they positioned L's "subjective" experience as detached from a reality that was "in fact" relatively nonthreatening. In part through the construction of L's response as different from what is normal, L was also attributed responsibility for the events. By emphasizing the event as scripted, participants could hold L accountable for not "appropriately" reading and acting in accordance with what the situation required. They furthermore emphasized L's agency to suggest the ease with which (s)he could have resisted or left the situation, and hence to construct the sexual encounter as consensual.

In the final section, we elaborate upon the differences we noted between the male and female target conditions. These differences were not as pronounced as might have been expected because similar scripts were employed in response to both conditions. However, participants seemed to draw more easily upon the hookup script, gender stereotypes, and miscommunication discourse to explain the encounter between Lisa and Thomas compared to the encounter between Lucas and Thomas. Consequently, participants more explicitly constructed Lisa as responsible for failing to recognize the situation as a hookup and its associated risks for her.

\section{Event as Normal}

Participants generally framed the event as an unfortunate situation in which Thomas went "too far," but not as something that carried the connotations of sexual violence. To construct the event as "in fact" relatively normal and (hence) nonthreatening, participants used three main discursive strategies, as well as various sub-strategies (see Table 1 for an overview).
Broadly, participants strategically constructed the encounter as (a) in line with a hookup, (b) different from a "real" sexual assault, and (c) the actions of Thomas as predictable.

\section{Scripting the Event as a Hookup}

Participants placed the behavior of going home with someone after a night out in a framework in which it is "reasonable" to expect sexual interaction. To do so, they drew upon a particular sexual script that describes encounters of casual sex, or hookups. As described in the theoretical framework, a hookup script describes a meetup between two people who are not well-acquainted at a bar or party, and it includes actions such as drinking alcohol, going home together, and initiating sexual activity (Holman and Sillars 2012). All these elements were present in the vignette. Participants provided support for the reasonableness of anticipating a sexual encounter by referring to what "generally" happens in these cases: "In the majority of these type of situations it indeed ends between the sheets" (M41 FT) and "Usually it is the case after having been out for an evening, and someone asks you to go home with them to have another drink ... then a drink does symbolize something else" (F29 FT).

Utilizing the hookup script, participants could also pinpoint particular actions that "symbolize" or "signal" particular intentions. Participants treated these implicit meanings as part of the common knowledge regarding the "rules" of how casual sexual interactions evolve. Presumably everyone knows, for instance, that "People don't ask 'will you go home with me to drink another beer?' for no reason" (M40 MT). Although "something like that does not necessarily have to lead to sex ... you do then often think 'Oh something more than just a nice conversation will happen here"' (M36 FT). By drawing upon the hookup script, the sequence of the events in the vignette was thus constructed as common and predictable.

\section{Distancing the Event from a "Real" Sexual Assault}

In their reactions, participants tended to indirectly distance the scenario from a situation of "real" sexual assault, which would — based on the "real rape" script—presumably have included clear markers of coercion and violence. To do so, participants strategically obscured elements that suggested conflict and non-consent. For instance, although most participants (42 of 52) initially declared that $\mathrm{L}$ had clearly indicated (s)he was not interested in sex, they subsequently focused on the ways in which L failed to express refusal convincingly, suggesting for instance that if L "really didn't want it (...) then he could have gone home" (F1 MT; additional examples are reported in the section " $\mathrm{L}$ as responsible").

Additionally, whereas the occurrence of oral sex could have been interpreted as that which most closely resembles sexual violence, participants only fleetingly focused on this 
particular event in their response, and they often omitted it completely. Instead, participants tended to focus their response on the last fragment on L's leaving, by saying things like "I am glad she got out in time" (F22 FT), "it could have been much worse" (F17 MT), and "he did just leave and nothing happened" (M34 MT). References to "getting out in time" and "could have been much worse" reflect participants" comparisons with the alternative of "real" sexual assault. Compared to what could have happened, the current events were easily framed as not particularly severe: It was "good that Thomas also left it at that because he could, of course, also have pushed on" (F29 FT). Indeed, participants rarely described the event as coercive or unsafe. As one participant suggested, "It is something that you can simply talk about with your girlfriends. And eventually maybe even laugh about it, that it was all so awkward" (F20 FT). Only one participant explicitly validated an explanation related to coercion:

And I think that seeing the context of the first stories, it is quite clear here that also the part where she, like, blows him voluntarily, there is some form of intimidation or coercion in it. Ehm, so that that is against her will. I think that you could say that considering the context. (M43 FT)

Notably, whereas words such as "coercive" and "unsafe" signify interactions in the realm of sexual violence, words like "awkward" (F20 FT) or "super uncomfortable" (F17 MT) may be discursively employed to describe scenarios that amount to bad hookups, but still "just" sex (Gavey 2005; Hindes and Fileborn 2020; Lea and Auburn 2001).

The occurrence of oral sex was furthermore framed as noncoercive by depicting it as either a "question" of Thomas or an "initiative" by L. In the first case, participants reiterated Thomas' question without including L's immediate response of briefly performing oral sex. Participant 6 , for instance, skipped from Thomas asking for a blowjob to $\mathrm{L}$ leaving the apartment: "Yes, subsequently he goes another step further and asks if she wants to blow him. I think that that is kind of the point where she thinks like: 'Okay, I really need to go now"' (F6 FT). In this way, any conflict between the request and response of the actors disappeared from the narrative, masking the potential transgression of the event. The event no longer clearly included a moral agent who acts and a moral patient who is affected by that act (Gray and Wegner 2009). By exclusively focusing on Thomas' request without including the reaction, participants also effectively freed themselves of the task of explaining why L "gave in."

\section{Portraying Thomas' Behavior as Self-Explanatory}

Participants generally agreed that Thomas was "going too far" and being "inappropriate" (e.g., F1 MT; F2 FT; M4 FT; F5
MT; M16 FT; F33 MT) when he persisted in his sexual advances after $\mathrm{L}$ had indicated that (s)he was not interested. As one participant concluded: "it is absolutely clear that Thomas goes way too far here. That ... few people will disagree with that" (F33 MT). However, by aligning his behavior with normative sexual scripts and gender stereotypes, participants also portrayed Thomas' behavior as predictable and hence not particularly shocking: "I do find the assumption of the guy in question understandable. By which I am not saying that it is right, but it is understandable" (M41 FT). In this way, participants seemed to deemphasize Thomas' intentionality and diminish his blameworthiness. As stated by one participant, for instance:

I don't think it is necessarily wrong that Thomas tries something because, eh, yes, you know she goes home with him and of course that is no, eh, green light to do everything and assume that sex will also immediately follow and all those things. But I do think that, eh, that there is a certain signal maybe, that Thomas has understood a certain signal coming from her. (M9 FT)

Here, the participant tentatively suggested that although Thomas should not have assumed sex as a given, it was not particularly strange that he did.

As has been found in previous research, participants borrowed from a discourse of miscommunication to explain, and at times justify, Thomas' sexual advances and persistence (Frith and Kitzinger 1997; Hindes and Fileborn 2020; Jeffrey and Barata 2019). In the previous extract, this was illustrated by framing as plausible "that Thomas has understood a certain signal coming from her." Participants additionally endorsed the possibility that L was "playing hard to get" (M9 FT; F11 FT; M16 FT; M48 MT; M50 FT) or "shy" or "insecure" (F1 MT; M16 FT; M48 MT), and in need of a little more encouragement. For instance,

And well, [Thomas] actually noticed that Lisa did nothing against it. Or well, she did take her, ehm, his hand away, but he could have perhaps seen that as, well, playful, or he did not realize because he was very drunk. Yes, you don't know. (F11 FT)

Here, the participant initially described Lisa's non-verbal refusal as "doing nothing," and while correcting herself, still suggested that Lisa's behavior could be easily misinterpreted. Hence, participants suggested the possibility that Thomas was not fully aware of his actions and portrayed the misinterpretation of signals as a plausible explanation for his persistence. Framing the event as essentially a matter of miscommunication downgraded its severity and constructed Thomas' actions as lacking intent, thereby diminishing his responsibility. 
In order to normalize Thomas' behavior, participants not only drew upon "common knowledge" based on scripts and miscommunication discourse, but also on intermingled gender stereotypes. Specifically, participants explained the event by framing Thomas as a particular type of man: presumably, a man who wanted sex, and was drunk on top of that. As such, both the event and Thomas' actions required little elaboration: "Sounds like quite a standard story of how that type of youth will behave themselves after they invite someone to their own apartment" (M16 FT). Another participant described Thomas as a "kind of a puberty boy: 'Oh I'm taking a girl home, something is going to happen,' those kinds of things" (F18 FT). Portraying Thomas' actions as "typically boy-like" (F32 FT), thus as simply an instance of "boys being boys" (Hlavka 2014), precluded the necessity to exert more explanatory effort to account for his behavior.

Indeed, in general, even though most participants did not approve of Thomas' behavior, they generally spent few words on explaining or excusing it. The reason for this might be that "the more socially entrenched the understandings, the less these understandings seem to require articulation" (Presser 2013, p. 85). Utilizing "group membership categories" (Edwards and Potter 1992, p. 160) such as a "type of youth" or "puberty boy" also resulted in a reduction of Thomas' individual responsibility. At times, the "explanation" sufficed that Thomas "remains a man and she the woman" (...) I find it logical that he then tries it again" (F23 FT). Thus, although Thomas' behavior was denounced as inappropriate, the ease with which it was placed within a familiar script of a normative sexual encounter and aligned with miscommunication discourse and traditional gender roles seemed to make it more excusable, or at the very least, less shocking.

\section{Lisa/Lucas as Abnormal}

The previous section elaborated upon the ways in which participants constructed the event, including Thomas' actions, as "normal" (i.e., predictable, not severe, and self-explanatory). The construction of the event as normal both required and resulted in a portrayal of $\mathrm{L}$ as abnormal. In order to maintain an account of the event as nonthreatening, participants framed L's reaction as (a) strange and foolish and (b) as something that could be explained by L's personality or mental state rather than by external (coercive) circumstances. In this way, participants could also acknowledge that L might "feel violated" by the encounter and express sympathy for L's experience without treating it as indicative of what "actually happened." Hindes and Fileborn's (2020) analysis of media reports on Grace's encounter with Aziz Ansari uncovered similar sense-making strategies that located the "problem" of the encounter in Grace's "subjective interpretation of the encounter" (p. 9, our emphasis).

\section{Framing L's Reaction as Incomprehensible}

Although participants were quick to denounce Thomas' actions as inappropriate, it was notable how little participants elaborated upon this judgment. Instead, participants predominantly focused on L's reaction to the situation and strategically framed this reaction as abnormal. They did so in various ways, including by direct references to L as "strange," "naïve," and "incomprehensible," by contrasting L's behavior to how participants themselves would act and by emphasizing the need to explain L's behavior. Participants seemed to suggest that the behavior most in need of explanation was L's decision to stay, her/his limited physical resistance, and her/ his engagement in oral sex. These elements might also be considered those that contradict prescriptive behaviors of a "legitimate victim" in a situation of sexual assault (Temkin and Krahé 2008).

In the following two extracts, for instance, participants quickly established that Thomas "is going too far," which is not "as it should be," but subsequently indicated that "the question is" why L reacted the way (s)he did. As such, participants seemed to hint that it was in fact L's behavior that required explanation and justification:

And then I think like, that guy has gone too far, that is stupid. He should have actually stopped and. But the question is, well, is that girl then so scared that she feels forced or, or whatever, to do this, because she does feel free enough after to say: 'I don't feel like it and I'm going to stop'. But she is, though, she is, she does consent to it. That, that I then again find strange. Or well, strange. For me, incomprehensible so to say. Because maybe I just cannot place myself in that girl very well, but I would say 'Girl, get up, go home.' (M9 FT)

Look, I get that Thomas thinks that Lucas is up for something seeing as he goes home with Thomas. But once on the couch, when Lucas says no and yet sits back down again, and Thomas tries it again ... is actually of Thomas ... is not really how it should be. But that Lucas freezes is to me always a very strange ... because I think like if someone touches you while you would not want that, well I would never permit it. (F1 MT)

Both these participants' responses included selfcomparisons and evaluative labels that suggested L's abnormality. Participants contrasted L's behavior to how they themselves would act and explicitly labeled L as "different." Through this comparison, L was designated as incomprehensible and foolish, whereas participants themselves were presented as sensible and thus unlikely to find themselves in a similar situation. 


\section{Seeking Explanations within L}

As we mentioned before, participants rarely raised the suggestion that $\mathrm{L}$ did not feel able to leave due to external circumstances such as a coercive atmosphere and pressure from Thomas. Instead, explanations were generally sought in L's own (altered) mental state. L's sense of reality was presented as diminished and confused by portraying it as under the influence of alcohol, shock, and fear: "because well, under the influence you are just not completely yourself" (F33 MT), and you might be "a little overwhelmed by the situation, and perhaps somewhat fearful" (M46 MT; also F8 MT; M30 MT). For instance, participant 52 focused on Lucas' anxiousness as a reason for staying: "And from Lucas, well, yes I do get him on the one hand, that just because of the nerves he does not know how easily he can actually leave" (M52 MT). Other participants focused on the potential influence of alcohol:

And eventually he does something that she says that she does not like. Well, that's not proper. But, well. There is probably booze involved, there is booze involved. And so I get that she cannot push away, and just goes home and just says "Later, I'm going home." (F20 FT)

Although the participants offered different explanations for L's behavior, they simultaneously subtly portrayed it as something unreasonable. For instance, participant 52 mentioned an "on the one hand" without mentioning what he would place "on the other hand," but the contents of the counter-position are implied by stating that Lucas did not realize that actually he could have easily left. Additionally, participant 20 labeled Thomas' behavior as inappropriate before moving on to alcohol as a potential explanation. As it turned out, however, this explanation was offered to "justify" Lisa's reaction, whereas Thomas' behavior was not elaborated upon.

Explanations based on L's (altered) mental state had several practical consequences. They placed $\mathrm{L}$ in the realm of the abnormal that was detached from a nonthreatening "objective reality" and thereby somewhat diminished L's agency and culpability (F8 MT: "it also isn't his own fault because he obviously for a moment didn't know what to do"), without transferring complete responsibility to Thomas. Potentially, this focus also allowed participants to express sympathy for L's "subjective" experience, without rendering that experience an accurate reflection of the "actual" events. Whereas Participant 23 sought an explanation for the event in Lisa's alcohol consumption and ineffective communication for instance, this participant also expressed that "it is very sad for Lisa because, well, you would not want anyone to experience something like this, that you feel sexually used" (F23 FT).

\section{Lisa/Lucas as Responsible}

The previous section demonstrated that although participants provided some justification for L's reaction, they thereby also implied that L's behavior was not as would be expected from a "normal" or "reasonable" person. The suggestion that L failed to be aware of what is generally presumed common knowledge and did not act as other people would did function to depict L not only as abnormal, but also as accountable. Participants strategically positioned $\mathrm{L}$ as responsible by (a) emphasizing the event as clearly scripted and (b) appealing to L's agency to suggest (s)he could have acted differently. Thus, participants suggested that L should have recognized the situation as a hookup and if (s)he did not want to perform in accordance with that script, (s)he should have undertaken one of a very few justified actions in order for the event to be recognized as sexual assault.

\section{Emphasizing the Event as Scripted}

As demonstrated in the first section, participants treated the story described in the vignette as one that is easily identifiable as a hookup script in which certain actions (e.g., going home together; drinking together) point toward the likelihood of certain outcomes (e.g., sexual activity). By scripting the situation as a typical hookup, participants insinuated both that actions within such a situation follow a fixed sequence and that people are generally aware of how the event is likely to unfold. As such, L was depicted as accountable for not taking sufficient note of the possible implications of entering the given situation and for not performing the appropriate actions in order to escape from that situation.

Participants implied, for instance, that $\mathrm{L}$ should have recognized the situation as a hookup, including the anticipation of sex as a key script component:

Yes he has just really used her, but I also find that it has really been her own, eh, responsibility. She has been very naïve and she knew, you know, beforehand of course already that when a guy asks you if you'll go home with him, what can happen then. Well, that is thus exactly what happened. (F32 FT)

As illustrated in this extract, participants referred to "common knowledge" - things about which people are expected to know - to construct L both as abnormal and responsible. By labelling Lisa as naïve, participants suggested that Lisa was in some way abnormal because she did not sufficiently realize, or act upon, what people generally understand as "reality." Participants additionally expressed that even if Thomas acted inappropriately, L should have foreseen the development of these events and thus was assigned responsibility for deciding to go home with Thomas. 
By emphasizing a fixed and thus predictable sequence of events, participants also implied that only a limited range of actions were available to $\mathrm{L}$ if (s)he wished to counter the development of events and, specifically, refuse sex. Participants implied that a "clear" rejection of sex should be articulated explicitly, repeated several times, and accompanied by specific actions. In contrast, participants framed L's actions - particularly going home with Thomas and staying after his first advances - as liable to misinterpretation. To portray L's refusal to sex as unclear and unconvincing, participants again drew upon the hookup script and miscommunication discourse (also Frith and Kitzinger 1997; Jeffrey and Barata 2019). Although L articulated that (s)he had no interest in sex and pushed Thomas' hand away, these actions were attributed only a temporary effectiveness and validity (also Ehrlich 2001). For instance, where Participant 2 initially stated that Lisa "clearly indicated that she did not want sex," the participant subsequently noted within the same break that when Thomas persisted "he in that sense does go too far ... [but] well, she should have actually also indicated that it is not okay" (F2 FT). As such, participants suggested that L's behavior made it reasonable, or at least not particularly shocking, that Thomas continued his sexual advances.

Another participant mentioned that Lucas "agrees to stay and continue with the movie," and he was "not surprised that at this moment eh... Thomas now goes through with it" (M31 MT). Although the participant did not explicitly state why he was not surprised that Thomas persisted, the temporal ordering of the events indicated a connection to the fact that Lucas did not leave. Most participants agreed that the most "appropriate" action to undertake when one is not interested in sex was to leave: "I would have left I think. I also do not understand why he does not do that. If you feel uncomfortable with it, then you should just go" (M46 MT). In this extract, the participant discursively transitioned from using "I" to "he" to the general "you" to imply a universal rule that ought to be followed in a situation like this when one is not interested in sex. Yet another participant noted "How super stupid that Lisa still stays, while it was quite clear what the intentions of Thomas were. Namely, to go to bed with her," and concluded "Not that it's really entirely her fault, but it is also not Thomas' fault because she had not communicated well" (F23 FT). Clearly, this participant suggested that articulating refusal to sex while staying at the apartment amounted to ineffective communication.

In these responses, it appeared that the more defined and fixed a script was portrayed to be, the fewer actions were framed as permissible for L. In other words, the more clearly the intention of sex was emphasized, the more pressing the demand that L express non-consent by leaving the situation or alternatively by hitting and shouting. A course of action that included stating one's position, potentially followed by an agreement to watch a movie, were not accorded the status of valid alternative responses. Hence, $\mathrm{L}$ was held accountable for not breaking with the anticipated script and refusing sex in a sufficient manner.

\section{Appealing to L's Agency}

The previous section demonstrated how participants constructed only a few actions as "correct responses" to the given situation, effectively limiting L's agency. Yet L could only be held accountable for not performing these actions precisely through the suggestion that (s)he could have easily acted differently if (s)he had wanted to. Indeed, participants portrayed L as having "in fact" sufficient agency to be able to express and enact their refusal freely. As explicitly stated by one participant, for example, "At any moment she can still say 'I want to go,' but she doesn't do that," leading the participant to conclude that "it is not good what he [Thomas] does, but she could have easily prevented this" (M47 FT).

Participants not only emphasized L's agency when suggesting that L might have easily acted in a way that would have resolved the situation, but also framed L's staying and engagement in oral sex as intentional. Whereas the vignette's description of L "obeying" when Thomas asked for a blowjob might have been interpreted as a response to an authoritative and coercive demand, for instance, participants generally employed reformulations such as "agreeing" (e.g., M9 FT; M46 MT) to point to initiative-taking and egalitarianism between parties. Participants noted that "he [Lucas] lets himself be persuaded" (F1 MT), "that he [Lucas] has stopped it, and subsequently blows him" (M30 MT), and "she has blown him for a while, and only after that stopped" (F13 FT). In these responses, "the appeal to agency actually helps to mystify the power dynamics that are in play" (Cahill 2016, pp. 756-757), thus depicting the oral sex as L's own initiative and hence part of a normal sexual encounter. Indeed, by framing L's behavior as agentic, participants tentatively precluded the possibility of sexual assault:

Now of course, the question is, or well, I am just saying something right, the question is, is this now for instance, has he, has he now raped her? Because he asked it, she agrees, in the first instance. And she, and she, and she blows him. So ehm, and she then stops, and then she leaves. (M9 FT)

\section{Comparison Male and Female Target Condition}

The previous sections have illustrated how participants construed the event described in the vignette as "normal" and nonthreatening, while they depicted L as abnormal and responsible. Although this tendency was found in both the male 
and female target conditions, several differences were noted in the overall responses of participants.

\section{Construction of the Event}

As also reflected in the extracts mentioned in previous sections (e.g., "Event as Normal": F29 FT; M36 FT; F32 FT), references to the hookup script and Thomas' predictable behavior were more prominent as explanatory tools in the female target condition compared to the male target condition. Especially in reaction to the first fragments, participants described the encounter at the party between Thomas and Lisa as a "standard story, not very much out of the ordinary" (F27 FT) or as a "normal interaction between man and woman" (M4 FT) in a setting where "it often happens that men pursue the women" (M10 FT). Subsequently, participants constructed the act of drinking and going home together as a normal precursor to sexual engagements: "The general expectation within the student world is that you then go to bed with someone" (F23 FT).

Even at later moments in the story, when Lisa had indicated that she was not interested in sex, participants normalized the encounter. Specifically, by employing sexual scripts and gender stereotypes, participants proposed that the encounter between Thomas and Lisa might have been a "classic miscommunication" (M41 FT; also M4 FT; F23 FT; F29 FT; M36 FT) where Thomas "just really didn't realize the signals that she gave" (F11 FT). As described more elaborately by the following participant:

Yes this is something that really, what I gather from other stories in my surroundings, or well, that it happens more often that a boy is with a girl and that she resists, and eh. But how I understand it from other guys is that they interpret it more like she is playing hard to get. So that she does want it, only does not want to admit it (...) And so she should be very clear about that I think. If you're not clear about that then it becomes difficult. Then the guy does not know exactly what is going on. (M50 FT)

In this extract, the participant drew upon "common knowledge" about sexual interactions between men and women that he gleaned from stories of friends and acquaintances as a means to support his argument. Presumably, the encounter between Thomas and Lisa was more easily framed as a "typical" hookup because normative sexual scripts mostly revolve around a heterosexual dyad (Wiederman 2005). As such, "common knowledge" derived from sexual scripts and gender stereotypes provided participants with more tools to construct a nonconsensual sexual encounter between Thomas and Lisa as normal.
Instead, a less coherent framework seemed available for making sense of the encounter between Thomas and Lucas, presumably because "normally you just don't hear these types of stories" (M34 MT). As explicitly stated by one participant:

That is intense to read. There is a turning point in the story, I had not expected that. Especially because they are two men you could, you would more quickly expect it of a man and a woman if the woman goes home with the man. (F37 MT)

Whereas Thomas' behavior was in general easily dismissed as typical and unsurprising, participants thus also tended to describe it as unusual or strange in the male target condition. As suggested by participants, if one had not been aware of the topic of the study, "it is of course a weird turn of events" (F26 MT; also M31 MT). Participants indicated that Thomas was "weird and really enormously inappropriate" (F7 MT), "just weird" (F17 MT), and that it was "strange that Thomas continued while Lucas clearly used his hand to signal 'Stop, I don't want this"' (F8 MT). Participants even expressed they already found it strange that Thomas invited Lucas to his apartment (M34 MT; M42 MT).

Although participants generally seemed less prone to construct the encounter between Thomas and Lucas as "normal," for instance by framing it as a "typical" case of miscommunication or misunderstanding, they also drew upon normative sexual scripts to make sense of the encounter. Indeed, it should be noted that even if descriptors that signaled abnormality seemed more prominent in the male target condition, most participants expressed no surprise regarding the gender of the actors, and the first fragments of the vignette were generally described as "quite a normal story" (F5 MT; M52 MT). Presumably, participants knew to expect a sexual encounter-because they had been so informed prior to the study - and so they were quick to place the (initial) interaction between Thomas and Lucas within a hookup scenario. As such, "Lucas could have expected that something like that was going to happen" (F8 MT).

Although not many participants explicitly mentioned the actors' presumed sexual orientation, two participants employed Lucas' bisexual orientation to normalize the outcome of the event:

In that situation I can imagine that Lucas maybe lets himself be seduced to doing too much that he actually does not want to do. Compared to if he were a guy who is just self-confidently homosexual and eh... is also open about that. He indeed also says that he is bisexual, so maybe he is still experimenting a bit. (F1 MT)

Here, Lucas was constructed as a "insecure boy who didn't really know what he wanted" and "because of that ambiguity 
Thomas thought things that were not correct" (M48 MT). These responses also demonstrated once more how the normalization of the event corresponded with responsibility assignment.

\section{Assignment of Responsibility}

The fact that participants portrayed the situation as more clearly scripted for Lisa seemed to result in a greater assignment of responsibility to her compared to Lucas. Lisa in particular was expected to be able to read a hookup script into the scenario, as well as the possible risk this entailed for her. Participant 2, for instance, stated that:

It is a risk which she takes, and she can't properly lock her bike, which means that she was really not clearheaded anymore. But well, on the other hand it should just be possible that she goes with him (...) but yes, ehm, it is somewhat naïve to immediately go home with him. (F2 FT)

In this extract, the participant implied that even if ideally "it should just be possible" to go home together, in "reality" this type of action amounted to risky and naïve behavior. This relation between scripts and responsibility assignment has also been found in Anderson and Doherty's (2008) study, where female rape was construed as a predictable risk that could be anticipated and thus managed by the (pre-)victim.

The following extract aptly illustrates how participants portrayed the situation for Lisa as particularly scripted and thus risky:

So it is a situation that you maybe actually want to prevent, maybe that is indeed almost the painful conclusion. If you are both under the influence, you are a boy and a girl in such a situation but you are not interested, just don't even go home with each other at that point in time. Because then you prevent that sort of situation. Not to place blame somewhere, but purely as, yes, conclusion. (M41 FT)

This extract demonstrates how participants' utilization of scripts and gender stereotypes left particularly little room for Lisa to act "appropriately." In this case, the participant presented a particularly deterministic viewpoint in which he tentatively suggested that the only "solution" for Lisa would have been not to go home together at all.

Strikingly, many participants (14 of 25) at least once explicitly described Lisa or her behavior as "naïve," "foolish" or "not clever." In contrast, only a few participants (4 of 27) evaluated Lucas and his decisions similarly, and none of them used the words "naïve" or "foolish." Instead, they employed milder expressions such as "not so very smart" (F5 MT), "not very sensible" (F25 MT; M44 MT), and "it would have been more sensible if" (M28 MT). Potentially, although Lucas may have also been expected to be familiar with the hookup script, for him this did not necessarily entail a situation of risk: "Lucas and Thomas seem to me like normal friends, not much can go wrong I think" (M21 MT). As articulated by another participant:

Yes, maybe this sounds stupid but as a guy it is ehm, that is perhaps easier because you are not warned for it as much. Ehm, so I get what Lucas does and until now the situation is also not particularly strange. (M33 MT)

Hence, Lucas' actions were initially constructed as more excusable, whereas for Lisa they were identified as "precipitating victim behavior." As such, Lisa was judged more severely than Lucas was for behaviors such as going home with Thomas and staying at his place after her initial rejection of sex.

\section{Discussion}

The present study investigated how observers made sense of a sexual encounter that included expressions of non-consent by the targeted party, but did not adhere to scripts of sexual violence as employed in common discourse. We were particularly interested in what interpretative repertoires participants drew from in order to describe the event and determine whom to hold accountable.

Our analysis demonstrated that participants strategically constructed the situation as normal and the actions of the targeted party (i.e., Lisa/Lucas) as abnormal. The situation was portrayed as normal predominantly by reference to what has been labeled the hookup script (Holman and Sillars 2012; Littleton et al. 2009). This script was made salient by participants through discursive strategies of describing predictable stages of the event, speaking of common knowledge, and using hypothetical examples and general descriptions in their responses (Frith and Kitzinger 2001). Similar to the findings by Jeffrey and Barata (2019), invoking the hookup script and related miscommunication discourse enabled participants to frame the sequence of events as predictable and not particularly severe as well as the initiating party's behavior as unsurprising. Elements that could have been scripted as indicative of sexual assault - specifically, the various expressions of non-consent and the oral sex-were instead largely obscured.

Contrary to the depiction of the event as common and understandable, Lisa/Lucas was construed as abnormal. This was done explicitly by using words such as "strange" and "incomprehensible," but also was achieved through self-comparisons. Furthermore, the search for explanations of Lisa/Lucas' behavior functioned to indicate that this behavior 
was not as one would expect. Explanations were mostly sought in their (temporary) mental state, which was described as panicky and inebriated, or in their naivety. These explanations also positioned Lisa/Lucas as at least in part accountable for what had happened. As the targeted party, they were specifically held responsible for not being sufficiently aware of, and inadequately breaking with, the invoked script. Participants rarely entertained the possible explanation that Lisa/Lucas did not feel able to leave due to external (coercive) circumstances. Their sense-making practices hence echoed those previously found in rape perception research, where complainants were evaluated "against the standard of the 'normal' subject of legal discourse - the rational, autonomous, freely-choosing individual of classic liberal theory" (Ehrlich 2001, p. 92).

In our comparison of observers' sense-making strategies in female versus male target conditions, both similarities and differences were found. In both conditions, participants tended to (initially) frame events in line with the hookup script and made little explicit reference to gender stereotypes. Still, some support was found for the suggestion that "Our understandings of the normative cultural scripts (or stereotypes) for male and female (hetero)sexuality are likely to be lenses through which we read all manner of relevant detail for assessing safety and risk" (Gavey 2005, p. 209). Results pointed to the likelihood that, compared to the male target condition, participants scripted the expected sequence of events for Lisa as more definite and fixed. In this condition, the narrative of miscommunication was particularly prominent, and only a very few actions were deemed appropriate for her. Similar to the findings by Anderson and Doherty (2008), participants seemed to hold Lisa more responsible for knowing the applicable script and the risk this entailed for her. They were more inclined to describe Lisa and her behavior as foolish and naïve compared to milder evaluative descriptions of Lucas and his behavior.

Our results demonstrate that besides evaluating events and actors in terms of "bad" versus "good," an equally powerful evaluative framework seems to consist of judgments of what is "normal" (expected, familiar) versus "abnormal" (weird, unrelatable). Previous research has similarly suggested that dominant discourses of sexuality and gender can function to normalize situations of sexual coercion and violence (Hlavka 2014; Jeffrey and Barata 2019). As a consequence of detaching the subjective and "abnormal" experience of $L$ from a predictable and non-severe "objective" normality, the event was rendered largely nonthreatening.

\section{Practice Implications}

In a time where definitions of sexual assault are increasingly broadening and people are more likely to use a variety of (online) platforms to share negative sexual experiences, our study may provide important insights regarding third-party reaction to such stories. Whereas reactions on social media are typically limited to overt acknowledgments or rejections of the situation as sexual assault and the actor as victim, our study shed more light on the sense-making practices that underlie such judgments. Scholars have stated that "a defining characteristic of an institutionally-dominant ideological frame is its capacity to be naturalized - to be accepted as commonsensical" (Ehrlich 2001, p. 65) and that "what gets stated in an explanation is crucially dependent on what is already shared knowledge" (Draper 1988, p.29). Hence, explanations that participants provided in the present experimental context can give insight into what ideas are presumed common knowledge in their own social environments. Hookup scripts were, for instance, firmly embedded in participants' understandings of student life.

Although scripts can be useful tools to make sense of one's experiences, it seems reasonable to challenge not just constructions of "real rape," but also scripts of normative sexual encounters. Refusal to portray (sexual) encounters as involving fixed progressive stages and prescribed roles and actions may leave actors with more leeway to pursue the type of connection they hope to establish with someone. Although we are aware of the ideologically wistful note in this suggestion, we do believe media, education systems, art projects, etc. (can) all contribute to offering alternative possibilities of social interaction and loosening traditional scripts. Initiatives such as the Swedish \#talkaboutit campaign, which encouraged sharing stories of "grey area" sexual interactions (Karlsson 2019), may broaden the available discourse for people when talking of experiences of sexual violation (Alcoff 2018). People who have suffered from negative sexual experiences or sexual assault may also feel freer to open up about such experiences and seek support in their environment when they are not forced to frame their experience within limiting, predominantly legal, discourse (Gash and Harding 2018). Finally, by acknowledging that experience is largely shaped through discourse (Gunnarsson 2018; Hindes and Fileborn 2020), a greater variety in available scripts and discourses may aid individuals' sense-making.

\section{Limitations and Future Research Directions}

The current study innovatively employed the ATSS method in combination with discourse analysis to investigate participants' sense-making practices in reaction to a (transgressive) sexual encounter. However, the chosen method may also have inadvertently influenced participants' responses in several ways. First, in accordance with ethical considerations and informed consent, participants were informed beforehand that the vignette contained details about sexually inappropriate behavior. This may have directed participants' sense-making strategies, prompting them to speak in terms of what they 
considered normal or expected from the first fragment onward. It additionally likely affected participants' expectations of the sexual orientations of the actors in the vignette. Because participants were informed prior to the study that the vignette involved a sexual encounter, the participants who read about Thomas and Lucas were likely to expect them to interact in a sexual manner and to thus view them as gay or bisexual. These expectations may have in turn activated different expectations based on the scripts and stereotypes that people hold in relation to men with these sexual orientations. In this context, another limitation is that we did not ask participants about their own sexual orientation, although this could have affected how they made sense of the vignette.

Second, participants' responses in the current design were researcher-prompted by the presentation of specific vignette fragments and were constrained to one minute following each fragment. Although in a sense participants "interacted" with the vignette and were aware that the researchers would eventually listen to their responses, participants' responses were not part of a typical social interaction. Hence, it is important to be aware that speakers may present their narratives differently, for instance by focusing more on speaker accountability, in a different and more social context. Furthermore, participants may have been influenced by the fact that the vignette was presented from the narrative viewpoint of L. Potentially, for example, participants reacted more empathetic to $L$ than they would have done if the story had been presented from a different viewpoint (i.e., that of Thomas or a third-person perspective). This would be an interesting topic for future research.

Finally, responses have been collected from a specific subgroup of Dutch university students who were willing to express their opinions about a topic related to sexual (inappropriate) behavior. Ours is not a representative sample, and patterns in the data may not generalize to other (sub)groups of observers. Future research could expand on the type of setting, participant pool, and contents and form of the vignette to gain a broader understanding of the elements people employ in constructing a sexual encounter as normal or transgressive and its actors as blameless or accountable. It additionally would be interesting to investigate reactions to sexual encounters that include a woman who persistently pursues sex and to examine potentially different sense-making practices of male versus female participants.

\section{Conclusion}

The current study lent support to the notion that dominant discourses of sexuality, violence, and gender can be strategically employed to render nonconsensual sexual encounters normal and (hence) nonthreatening. Rather than arguing that observers should instead categorically label such an encounter as rape or sexual assault, we suggest there is value to acknowledging that sexual violence and negative sexual experiences can indeed be ambiguous (Alcoff 2018; Cahill 2016; Gavey 2005). Maintaining a discursive "grey area" might not only allow for a deeper exploration of the relationship between normative sex, sexual assault, and gender, it may also provide people with more room to share experiences of violation that they do not (wish to) define as clearly one thing or another. Even for people who do clearly define their own experiences as sexual assault, sharing these experiences might be easier if they are not forced to fit them within "clear-cut" definitions of sexual violence.

Funding This research was supported by the Nederlandse Organisatie voor Wetenschappelijk Onderzoek [grant number 406-15-157] and Fonds Slachtofferhulp [number 17.01.03]. We thank Dr. Kathy Doherty for her involvement and valuable input during the analytic process.

\section{Compliance with Ethical Standards}

Conflict of Interest The authors declare that they have no further conflicts of interest.

Informed Consent All respondents gave informed consent. The study was approved by the Tilburg Law School Ethics Review Board.

Open Access This article is licensed under a Creative Commons Attribution 4.0 International License, which permits use, sharing, adaptation, distribution and reproduction in any medium or format, as long as you give appropriate credit to the original author(s) and the source, provide a link to the Creative Commons licence, and indicate if changes were made. The images or other third party material in this article are included in the article's Creative Commons licence, unless indicated otherwise in a credit line to the material. If material is not included in the article's Creative Commons licence and your intended use is not permitted by statutory regulation or exceeds the permitted use, you will need to obtain permission directly from the copyright holder. To view a copy of this licence, visit http://creativecommons.org/licenses/by/4.0/.

\section{References}

Alcoff, L. M. (2014). Sexual violations and the question of experience. New Literary History, 45(3), 445-462. https://doi.org/10.1353/nlh. 2014.0030.

Alcoff, L. M. (2018). Rape and resistance. Cambridge, UK: Polity Press. Anderson, I. (2007). What is a typical rape? Effects of victim and participant gender in female and male rape perception. British Journal of Social Psychology, 46(1), 225-245. https://doi.org/10.1348/ 014466606 X101780.

Anderson, I., \& Doherty, K. (2008). Accounting for rape: Psychology, feminism and discourse analysis in the study of sexual violence. East Sussex, UK: Routledge.

Bates, E. (2016). Current controversies within intimate partner violence: Overlooking bidirectional violence. Journal of Family Violence, 31(8), 937-940. https://doi.org/10.1007/s10896-016-9862-7.

Burt, M. R., \& Estep, R. E. (1981). Who is a victim? Definitional problems in sexual victimization. Victimology: An International Journal, 6(1-4), 15-28. https://doi.org/10.1111/1471-6402.00103.

Byers, E. S. (1996). How well does the traditional sexual script explain sexual coercion? Journal of Psychology \& Human Sexuality, 8(12), 7-25. https://doi.org/10.1300/J056v08n01_02. 
Cahill, A. J. (2016). Unjust sex vs. rape. Hypatia, 31(4), 746-761. https:// doi.org/10.1111/hypa.12294.

Caringella, S. (2008). Addressing rape reform in law and practice. New York: Columbia University Press.

Christie, N. (1986). The ideal victim. In E. A. Fattah (Ed.), From crime policy to victim policy (pp. 17-30). Basingstoke, UK: Macmillan.

Cohen, C. (2014). Male rape is a feminist issue: Feminism, governmentality and male rape. Hampshire: Palgrave Macmillan.

Crotty, M. (1998). The foundations of social research: Meaning and perspective in the research process. Sydney: Sage Publications.

Davies, M., \& Rogers, P. (2006). Perceptions of male victims in depicted sexual assaults: A review of the literature. Aggression and Violent Behavior, 11(4), 367-377. https://doi.org/10.1016/j.avb.2006.01. 002 .

Davison, G. C., Robins, C., \& Johnson, M. K. (1983). Articulated thoughts during simulated situations: A paradigm for studying cognition in emotion and behavior. Cognitive Therapy and Research, 7(1), 17-39. https://doi.org/10.1007/BF01173421.

Deming, M. E., Krassen Covan, E., Swan, S. C., \& Billings, D. L. (2013). Exploring rape myths, gendered norms, group processing, and the social context of rape among college women: A qualitative analysis. Violence Against Women, 19(4), 465-485. https://doi.org/10.1177/ 1077801213487044.

Doherty, K., \& Anderson, I. (2004). Making sense of male rape: Constructions of gender, sexuality and experience of rape victims. Journal of Community \& Applied Social Psychology, 14(2), 85103. https://doi.org/10.1002/casp.765.

Draper. (1988). What's going on in everyday explanation? In C. Antaki (Ed.), Analysing everyday explanation: A casebook of methods (pp. 15-31). London: Sage Publications.

Dunn, J. L., \& Powell-Williams, M. (2007). "Everybody makes choices": Victim advocates and the social construction of battered women's victimization and agency. Violence Against Women, 13(10), 977 1001. https://doi.org/10.1177/1077801207305932.

Edwards, D., \& Potter, J. (1992). Discursive psychology: Inquiries in social construction. London: Sage Publications.

Edwards, D., \& Potter, J. (1993). Language and causation: A discursive action model of description and attribution. Psychological Review, 100(1), 23-41. https://doi.org/10.1037/0033-295X.100.1.23.

Ehrlich, S. (2001). Representing rape: Language and sexual consent. London: Routledge.

Entman, R. M. (1993). Framing: Toward clarification of a fractured paradigm. Journal of Communication, 43(4), 51-58. https://doi.org/10. 1111/j.1460-2466.1993.tb01304.x.

Frith, H., \& Kitzinger, C. (1997). Talk about sexual miscommunication. Women's Studies International Forum, 20(4), 517-528. https://doi. org/10.1016/S0277-5395(97)87415-8.

Frith, H., \& Kitzinger, C. (2001). Reformulating sexual script theory: Developing a discursive psychology of sexual negotiation. Theory \& Psychology, 11(2), 209-232. https://doi.org/10.1177/ 0959354301112004

Gagnon, J. H., \& Simon, W. (1973). Sexual conduct: The social sources of human sexuality. Chicago: Aldine Press.

Gash, A., \& Harding, R. (2018). \#MeToo? Legal discourse and everyday responses to sexual violence. Laws, 7(21), 1-24. https://doi.org/10. 3390/laws7020021.

Gavey, N. (2005). Just sex? The cultural scaffolding of rape. New York: Routledge.

Goodman, S. (2017). How to conduct a psychological discourse analysis. Critical Approaches to Discourse Analysis across Disciplines (CADAAD), 9(2), 142-153. https://www.lancaster.ac.uk/fass/ journals/cadaad/wp-content/uploads/2017/12/09-Goodman.pdf.

Gray, K., \& Wegner, D. M. (2009). Moral typecasting: Divergent perceptions of moral agents and moral patients. Journal of Personality and Social Psychology, 96(3), 505-520. https://doi.org/10.1037/ a0013748.
Gunnarsson, L. (2018). "Excuse me, but are you raping me now?" discourse and experience in (the grey areas of) sexual violence. NORANordic Journal of Feminist and Gender Research, 26(1), 4-18. https://doi.org/10.1080/08038740.2017.1395359.

Hindes, S., \& Fileborn, B. (2020). "Girl power gone wrong": \#MeToo, Aziz Ansari, and media reporting of (grey area) sexual violence. Feminist Media Studies, 20(5), 639-656. https://doi.org/10.1080/ 14680777.2019.1606843.

Hlavka, H. R. (2014). Normalizing sexual violence: Young women account for harassment and abuse. Gender \& Society, 28(3), 337-358. https://doi.org/10.1177/0891243214526468.

Holman, A., \& Sillars, A. (2012). Talk about 'hooking up': The influence of college student social networks on nonrelationship sex. Health Communication, 27, 205-216. https://doi.org/10.1080/10410236. 2011.575540.

Jackson, S. (1978). The social context of rape: Sexual scripts and motivation. Women's Studies International Quarterly, 1, 27-38. https:// doi.org/10.1016/S0148-0685(78)90311-1.

Javaid, A. (2015). Male rape myths: Understanding and explaining social attitudes surrounding male rape. Masculinities and Social Change, 4, 270-294. https://doi.org/10.17583/mcs.2015.1579.

Jeffrey, N. K., \& Barata, P. C. (2019). The intersections of normative heterosexuality and sexual violence: University men's talk about sexual behavior in intimate relationships. Sex Roles. Advance online publication, 83, 353-369. https://doi.org/10.1007/s11199-01901110-3.

Kahn, A. S., Jackson, J., Kully, C., Badger, K., \& Halvorsen, J. (2003). Calling it rape: Differences in experiences of women who do or do not label their sexual assault as rape. Psychology of Women Quarterly, 27, 233-242. https://doi.org/10.1111/1471-6402.00103.

Karlsson, L. (2019). Towards a language of sexual grey zones: Feminist collective knowledge building through autobiographical multimedia storytelling. Feminist Media Studies, 19(2), 210-224. https://doi. org/10.1080/14680777.2018.1467944.

Krahé, B., Bieneck, S., \& Scheinberger-Olwig, R. (2007). Adolescents' sexual scripts: Schematic representations of consensual and nonconsensual heterosexual interactions. Journal of Sex Research, 44(4), 316-327. https://doi.org/10.1080/00224490701580923.

Lea, S., \& Auburn, T. (2001). The social construction of rape in the talk of a convicted rapist. Feminism \& Psychology, 11(1), 11-13. https:// doi.org/10.1177/0959353501011001002.

Littleton, H., \& Axsom, D. (2003). Rape and seduction scripts of university students: Implications for rape attributions and unacknowledged rape. Sex Roles, 49(9/10), 465-475. https://doi.org/10.1023/A: 1025824505185.

Littleton, H., Tabernik, H., Canales, E. J., \& Backstrom, T. (2009). Risky situation or harmless fun? A qualitative examination of college women's bad hook-up and rape scripts. Sex Roles, 60, 793-804. https://doi.org/10.1007/s11199-009-9586-8.

Loseke, D. R. (1999). Thinking about social problems: An introduction to constructionist perspectives. New York: Aldine de Gruyter.

MacKinnon, C. (1989). Toward a feminist theory of the state. Cambridge: Harvard University Press.

Marcus, S. (1992). Fighting bodies, fighting words: A theory and politics of rape prevention. In J. Butler \& J. Scott (Eds.), Feminists theorize the political (pp. 385-403). New York: Routledge.

Muehlenhard, C. L. (1988). "Nice women" don't say yes and "real men" don't say no: How miscommunication and the double standard can cause sexual problems. Women \& Therapy, 7(2-3), 95-108. https:// doi.org/10.1300/J015v07n02 08 .

Mulder, E., \& Bohner, G. (2020). Negative third-party reactions to male and female victims of rape: The influence of harm and normativity concerns. Journal of Interpersonal Violence. Advance online publication. https://doi.org/10.1177/0886260520914565

Presser, L. (2013). Why we harm. New Brunswick: Rutgers University Press. 
Rayburn, N. R., \& Davison, G. C. (2002). Articulated thoughts about antigay hate crimes. Cognitive Therapy and Research, 26(4), 431447. https://doi.org/10.1023/A:1016214632062.

Reitz-Krueger, C. L., Mummert, S. J., \& Troupe, S. M. (2017). Real men can't get raped: An examination of gendered rape myths and sexual assault among undergraduates. Journal of Aggression, Conflict and Peace Research, 9(4), 314-323. https://doi.org/10.1108/JACPR-062017-0303.

Rothgerber, H., Kaufling, K., Incorvati, C., Andrew, C. B., \& Farmer, A. (2020). Is a reasonable woman different from a reasonable person? Gender differences in perceived sexual harassment. Sex Roles. Advance online publication. https://doi.org/10.1007/s11199-02001156-8.

Roupenian, K. (2017). Cat Person. The New Yorker. Retrieved from https://www.newyorker.com/magazine/2017/12/11/cat-person

Ryan, K. M. (1988). Rape and seduction scripts. Psychology of Women Quarterly, 12(2), 237-245. https://doi.org/10.1111/j.1471-6402. 1988.tb00939.x.

Ryan, K. M. (2011). The relationship between rape myths and sexual scripts: The social construction of rape. Sex Roles, 65(11-12), 774-782. https://doi.org/10.1007/s11199-011-0033-2.

Sessions Step, L. (2007). A new kind of date rape. Cosmopolitan. Retrieved from https:/www.cosmopolitan.com/sex-love/advice/ a1912/new-kind-of-date-rape/

Silman, A. (2018). Aziz Ansari, 'cat person', and the \#MeToo backlash. The Cut. Retrieved from https://www.thecut.com/2018/01/azizansari-catperson-and-the-metoo-backlash.html.

Simon, W., \& Gagnon, J. H. (1986). Sexual scripts: Permanence and change. Archives of Sexual Behavior, 15(2), 97-120. https://doi. org/10.1007/BF01542219.

Temkin, J., \& Krahé, B. (2008). Sexual assault and the justice gap: A question of attitude. Oxford: Bloomsbury Publishing.
Van der Bruggen, M., \& Grubb, A. (2014). A review of the literature relating to rape victim blaming: An analysis of the impact of observer and victim characteristics on attribution of blame in rape cases. Aggression and Violent Behavior, 19(5), 523-531. https://doi.org/ 10.1016/j.avb.2014.07.008.

Walsh, K., \& Murphy, T. (2019). Irresolute endings and rhetorical poetics: Readers respond to Roupenian's “Cat Person.”. Style, 53(1), 88 104. https://doi.org/10.1353/sty.2019.0006.

Way, K. (2018). I went on a date with Aziz Ansari. It turned into the worst night of my life. Babe. Retrieved from https://babe.net/2018/01/13/ aziz-ansari-28355

Wetherell, M., \& Potter, J. (1988). Discourse analysis and the identification of interpretative repertoires. In C. Antaki (Ed.), Analysing everyday explanation: A casebook of methods (pp. 168-183). London: Sage Publications.

Wiederman, M. W. (2005). The gendered nature of sexual scripts. The Family Journal, 13(4), 496-502. https://doi.org/10.1177/ 1066480705278729.

Worthington, N. (2020). Celebrity-bashing or \#MeToo contribution? New York times online readers debate the boundaries of hashtag feminism. The Communication Review, 23(1), 46-65. https://doi. org/10.1080/10714421.2019.1704110.

Zanov, M. V., \& Davison, G. C. (2010). A conceptual and empirical review of 25 years of cognitive assessment using the articulated thoughts in simulated situations (ATSS) think-aloud paradigm. Cognitive Therapy and Research, 34(3), 282-291. https://doi.org/ 10.1007/s10608-009-9271-9.

Publisher's Note Springer Nature remains neutral with regard to jurisdictional claims in published maps and institutional affiliations. 